Editorial

\section{Servicio de Atención Odontológica Interdisciplinaria para Personas con Discapacidad}

\section{Interdisciplinary Dental Care Service for Persons with Disabilities}

González $\mathrm{H}^{1}$, Conti $\mathrm{R}^{1}$, Izurieta $\mathrm{G}^{1}$, Vera $\mathrm{A}^{1}$. Meza $\mathrm{M}^{1}$, de la Quintana D, Feijó MA, Hidalgo P.

Escuela de Posgrado, Facultad de Odontología, Universidad Nacional de Córdoba

Muchos pacientes presentan lesiones encefálicas, que se ponen de manifiesto por la falta de alguna función, que puede ser: sensorial, motora o sensitiva, y generan capacidades diferentes en estos pacientes.

La discapacidad nunca es producto de un solo factor, se produce por una multicausalidad de situaciones, que pueden ser congénitas y cuando abarcan un grupo de genes poligénicas 0 Adquiridas durante el periodo pre, peri o postnatal ${ }^{1}$.

Para el tratamiento de estos pacientes resulta esencial, aparte de conocer con certeza su diagnóstico y realizar su historia clínica, un primer contacto afectivo conociendo, por ejemplo, primeramente, su nombre. Esto permite establecer una relación, un diálogo, una empatía, que vaya más allá de las palabras. No existen protocolos clínicos para el tratamiento de estos pacientes debido a sus características propias. Es necesario interactuar a través de lazos afectivos que logren una actitud proactiva del paciente hacia el profesional.

Además, el acompañamiento de sus padres/tutores resulta esencial. Es destacable que estas familias tienen un profundo impacto psicoemocional al momento del nacimiento de un niño con enfermedades genéticas o congénitas La culpa, ansiedad, desesperación, frustración de deseos y ambiciones de personas en cuya familia nació un niño con una enfermedad hereditaria y defectos congénitos puede llevar a la ruptura de la familia, a sobrellevar el estigma a lo largo de la vida, a alterar estilos de vida, destruyendo el núcleo básico de nuestra sociedad.

Los datos epidemiológicos son determinantes. En Argentina la encuesta realizada por (ENDI) Encuesta Nacional de Personas con Capacidades
Diferentes, 2.176.123 personas padecen algún tipo de discapacidad. Estas cifras nos permiten obtener un perfil demográfico, epidemiológico, social y laboral que ayude a detectar las necesidades y las áreas a trabajar en prevención, atención y rehabilitación odontológica.

En décadas anteriores, en el contexto de la docencia de la Facultad de Odontología de la UNC, el abordaje de las personas con capacidades diferentes no estaba contemplado en el currículo de la carrera de Odontología, y no existía temas relacionados con la problemática que plantea el tratamiento de este tipo de pacientes, ni con la descripción de los síndromes más frecuentes.

Esta situación y el requerimiento permanente de padres que concurrían a la Cátedra de Odontopediatría con sus hijos con Capacidades Diferentes y necesidades odontológicas insatisfechas animaron a la Dra. Perla Hidalgo, Profesora Titular de la Cátedra, a concurrir al Hospital de Niños, a fin de capacitarse en la atención de este tipo de pacientes. La Profesora pudo interactuar con servicios profesionales médicos muy capacitados que contribuyeron a su formación en el área, a la adquisición de práctica en la atención odontológica pacientes niños con distintos síndromes y familiarizarme con diagnósticos de niños con patologías diversas.

Años posteriores, con la colaboración de los profesionales ayudantes de la cátedra se trasladó el Servicio a la Escuela de Posgrado, organizando el Servicio de Atención Odontológica Interdisciplinaria para Personas con Discapacidad.

Desde hace varios años el Servicio de Atención Odontológica de Personas con distintos tipos de discapacidades. Desde siempre las Autoridades de la Facultad de Odontología de la UNC, de la Escuela de Posgrado y todo el personal de secretaría han dado su apoyo incondicional al Servicio.

Esta conducta solidaria ha permitido extender la atención odontológica a otras instituciones y en tal sentido la Facultad de Odontología donó un consultorio odontológico completo al Instituto Helen Keller para la atención de niños y adolescentes con ceguera y otros problemas en la visión; a APADIM personas con Síndrome de Down o Trisomía 21, a la escuela diferencial "Carlos Besso" en el interior de la provincia donde concurren 60 a 80 niños y adolescentes con discapacidad y de condición humilde. 
Además el Servicio realiza ayuda solidaria para instituciones como "La Casa del Niño" que dirigía el Padre Aguilera en una localidad serrana de la provincia de Córdoba, Escuela Especial "María Montessori" de ciudad Capital. En una tarea docente complementaria dictamos un curso con el apoyo y colaboración de los profesionales asistentes a nuestro servicio con un programa teórico-práctico sobre distintos síndromes genéticos, congénitos y adquiridos que se presentan en nuestro medio.

Después de discusiones interactivas y reflexivas que la atención odontológica de personas con enfermedades discapacitantes constituye un desafío en la práctica odontológica, debido a la complejidad biológica, los principios bioéticos y valores morales a considerar se agrega el impacto emocional en la familia y la trascendencia al entorno social en que vive la persona con discapacidad.

El Servicio tiene como propósito brindar la mejor asistencia odontológica, previniendo afecciones severas, efectuando prevención y rehabilitación cuando la evolución del tratamiento así lo requiera a fin de lograr una mejoría en la Calidad de Vida de los pacientes; y además contribuir a la capacitación de profesionales de la Odontología en el abordaje de estos pacientes.

No hay un saber único con respecto al diagnostico y tratamiento de este tipo de patologías, por lo cual se hace imprescindible el trabajo interdisciplinario con médicos neurólogos, genetistas, y profesores de odontología de las distintas especialidades de nuestra casa de estudios y médicos de otros servicios.
La Fundadora de la Fundación PAR, que trabaja con personas con capacidades diferentes, Jacqueline C. de las Carreras dice 2 : "Todo lo que quiero es colaborar para que la vida de las personas con discapacidad sea más justa, más equitativa" y más humana.

Propiciamos la incorporación de las personas especiales a la Educación Inclusiva, ese término dice Ercoles se refiere a la capacidad del Sistema Educativo de recibir a las personas con discapacidad sin exclusión de ningún tipo ${ }^{3}$.

\section{Agradecimientos}

Se agradece la valiosa la ayuda incondicional de la Dra. Raquel Dodelson de Kremer, médica científica, investigadora, miembro del Conicet, distinguida en el medio social, con una extraordinaria formación académica, quien dirigió la Tesis de Doctorado sobre "Enfermedades Metabólicas Hereditarias. Correlación bio-patológica bucal" de la Prof. Dra. Perla Hidalgo y el reconocimiento a la médica Irma M. de Levstein por su asesoramiento y acompañamiento, a los profesionales de CEMECO, a los profesores de los servicios por los que he transitado.

\section{Referencias}

1. Secretaría de Graduados en Ciencias de la Salud. Facultad de Ciencias Médicas. UNC. "El abordaje de la discapacidad desde la atención primaria de la salud". $1^{\circ}$ Ed. Buenos Aires. Organización Panamericana de la Salud. OPS 2012.

2. Fundación PAR. Escuelas Inclusivas. $1^{\circ}$ Edición. Julio 2010. Buenos Aires. Argentina

3. Fundación PAR. Eroles, Carlos. Secretaria de Extensión Universitaria y Bienestar Estudiantil. Buenos Aires. Ed. Universitario de Buenos Aires. Endeba 2012. Buenos Aires. Argentina 